\title{
Large Renal Oncocytoma: A Rare Entity
}

\author{
Anuj Kumar ${ }^{1}$, Hemant Goel ${ }^{1}$, Umesh Sharma ${ }^{1}$, Arvind Ahuja ${ }^{2}$, Sumit Gahlawat ${ }^{1}$, Rajeev Sood ${ }^{1}$ \\ ${ }^{1}$ Department of Urology and Renal Transplant and ${ }^{2}$ Department of Pathology, PGIMER \& Dr RML Hospital, New Delhi, India.
}

\author{
Corresponding Author: \\ Dr. Hemant Goel \\ Email: hemant.doc81@gmail.com \\ This is an Open Access article distributed \\ under the terms of the Creative Commons \\ Attribution License (creativecommons.org/ \\ licenses/by/3.0). \\ Published \\ September 10, 2019
}

\begin{abstract}
Background: Renal oncocytoma accounts for 3 to $7 \%$ of all solid renal masses. Large renal oncocytomas (4 $\mathrm{kg}$ or more) are rare and only few cases are reported till date. Case Report: A 44 year old man presented with sudden onset right flank pain and large right abdominal lump. Further evaluation revealed a large heterogeneous mass not seen separately from right kidney. Intra-operatively a huge right renal mass (approximately $20 \mathrm{~cm}$ and $4.5 \mathrm{~kg}$ in weight) along with areas of necrosis and hemorrhage, completely replacing renal parenchyma was seen. Histopathology and immunohistochemistry was suggestive of oncocytoma. Conclusion: The renal oncocytoma can be differentiated from malignant RCCs by histopathology and immunohistochemically.
\end{abstract}

Keywords: Flank Pain, Kidney Neoplasms, Male, Renal Cell Carcinoma, Renal Oncocytoma.

\section{Introduction}

Renal oncocytoma accounts for 3 to $7 \%$ of all solid renal masses. Males are more commonly affected and the mean age of presentation is $6^{\text {th }}-7^{\text {th }}$ decade. Mostly oncocytomas are single and unilateral but in $4-5 \%$ cases may be bilateral and in $13 \%$ may be multifocal [1]. The oncocytomas are usually smaller and asymptomatic and cannot be reliably distinguished pre-operatively from renal cell carcinomas (RCCs). Large oncocytomas are rare however till date prognosis of larger oncoytoma is not reported differently from the smaller lesions.

\section{Case Report}

A 44 year old businessman presented with history of sudden onset right flank pain while he was resting on a chair. Pain was moderate in intensity and accompanied by nausea with no history of fever, hematuria or trauma. On examination, patient was pale looking with vitals within normal limits. There was mild tenderness in the right flank along with a large bimanually palpable lump of approximately $18-20 \mathrm{~cm}$ extending upto right iliac crest inferiorly and midline medially; superior margin was not defined discretely. There was no other organomegaly. Genital and pelvic examinations were normal. Laboratory examination revealed hemoglobin of $6.0 \mathrm{~g} / \mathrm{dL}$. Total counts, renal function, coagulation profile and urine routine microscopy were normal. On abdominal ultrasonography, large mixed echogenic space occupying lesion along with central necrosis was seen in right renal area, no lymphadenopathy noted, left kidney was of normal size, shape and position. Computed tomography with urography (CT IVU) revealed large heterogeneous mass $(19.6 \times 17.9 \times 15.2 \mathrm{~cm})$ in right renal area not seen separately from right kidney, abutting abdominal wall anteriorly, inferior surface of liver and gall bladder superiorly, crossing midline medially and displacing inferior venae cavae (IVC). The Hounsfield unit of the collection was 50. The solid component of mass showed moderate contrast enhancement in post contrast films [Fig.1]. Apart from complete bed rest, analgesia and antibiotic 


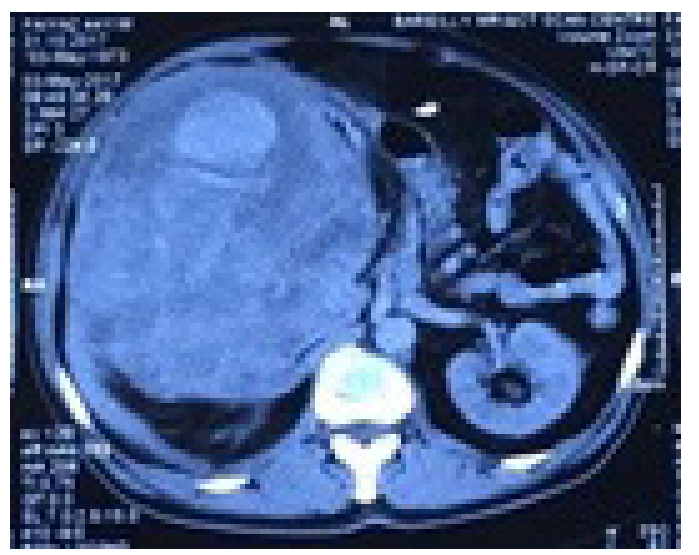

Fig.1: Well encapsulated, large heterogeneous renal mass having mass effect on surrounding structures with apparently normal renal vein and IVC (pushed medially).

were given along with packed red blood cell transfusions and right radical nephrectomy was done. Intra-operatively a huge right renal mass extending up to right iliac crest (approximately $20 \mathrm{~cm}$ and $4.5 \mathrm{~kg}$ in weight) with smooth surface and minimal perinephric adhesions, pushing IVC medially, single dilated right renal vein and artery, no hilar/retroperitoneal lymphadenopathy was noted [Fig.2]. On cut section tumor was heterogeneous along with areas of necrosis and hemorrhage and completely replacing renal parenchyma [Fig.3]. Histopathological examination showed a well encapsulated tumor with areas of hemorrhage and necrosis while microscopic examination showed tumor cells arranged predominantly in solid nests and lobules (10X) and tumor cells having round nuclei with evenly dispersed chromatin and conspicuous nucleoli and dense granular eosinophilic cytoplasm (40X) [Fig.4]. On immunohistochemistry tumor is EMA positive, CD117 positive and Vimentin negative [Fig.5].

\section{Discussion}

After renal cell carcinoma, oncocytoma is the $2^{\text {nd }}$ most common solid tumor of the kidney. To date, Demos et al. reported the largest and heaviest oncocytoma, measuring about $27 \times 20 \times 15 \mathrm{~cm}^{3}$ and weighed 4652 grams [3]. Banks et al. also reported the renal oncocytoma of $3090 \mathrm{~g}$ measuring about

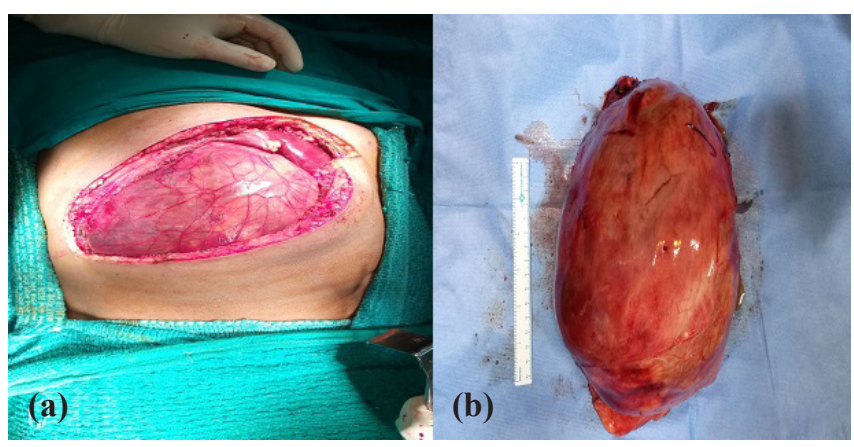

Fig.2: Intra-operative picture of right renal mass (a): in vivo (b): ex vivo showing well encapsulated, smooth surface renal mass with minimal perinephric adhesions.

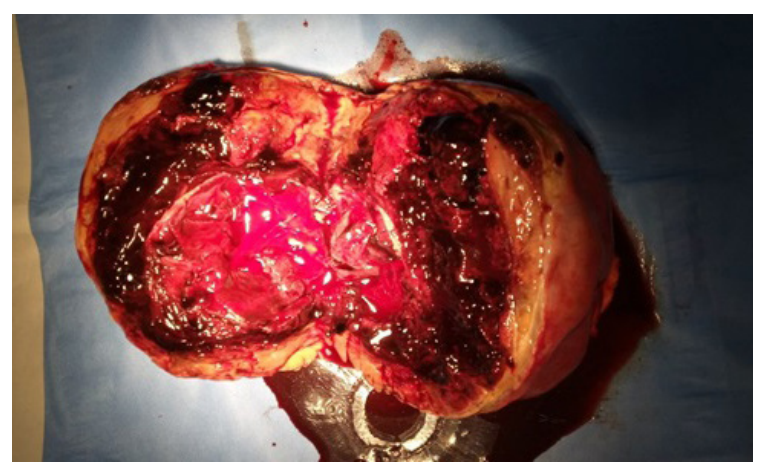

Fig.3: Gross examination of cut specimen showing heterogeneous renal mass with areas of hemorrhage and necrosis.
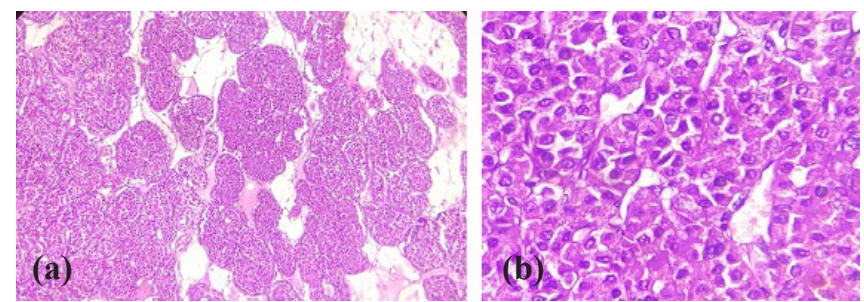

Fig.4:(a) Oncocytoma showing tumor cells arranged predominantly in solid nests and lobules (10X). (b): Tumor cells having round nuclei with evenly dispersed chromatin and conspicuous nucleoli and dense granular eosinophilic cytoplasm (40X).
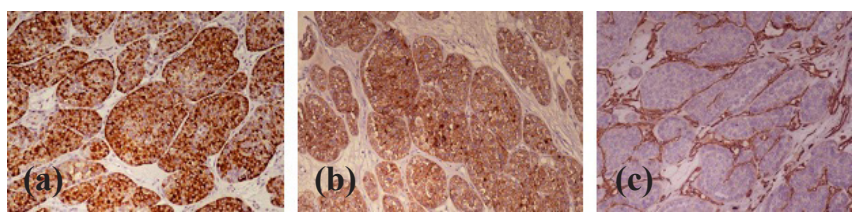

Fig.5: Immunohistochemistry (a): EMA positive (b): CD117 positive (c): Vimentin negative. 
$21 \times 18 \times 15 \mathrm{~cm}^{3}$ [4]. Kilic et al. reported another large oncocytoma weighing $2680 \mathrm{~g}$ and size $20 \times 15 \times 10 \mathrm{~cm}^{3}$ [5]. Unfortunately, clinically and radiologically most renal oncocytomas cannot be differentiated from malignant RCC.

Renal oncocytomas shows central stellate scar and spoke-wheel pattern of feeding arteries but are usually unreliable for preoperative differential diagnosis [6]. Hence should be treated as RCC with curative intent depending on the clinical circumstances. Usually oncocytoma are well encapsulated and are rarely invasive or associated with metastases even after attaining large size. Common cytogenetic findings for oncocytomas include the loss of the $1^{\text {st }}$ and Y chromosomes, loss of heterozygosity on chromosome $14 \mathrm{q}$ and rearrangement at 11q13. These genetics are characteristic and distinct from those described for the various subtypes of RCC [7]. Despite their benign behavior, coexisting RCC is seen in $10 \%$ to $32 \%$ of reported patients hence oncocytomas should be monitored closely and treated if there is any evidence of rapid growth [8].

\section{Conclusion}

Large renal oncocytomas $(>4 \mathrm{~kg})$ are rare and only few cases are reported till date, prognostic difference with smaller oncocytoma is not defined yet. Unfortunately, most renal oncocytoma's cannot be differentiated from malignant RCCs by clinical or radiographic evidence but can only be differentiated after resection by histopathologically and by immunohistochemically.
Contributors: AK, HG: manuscript writing, patient management; US, SG: manuscript editing, patient management; AA: histopathology and manuscript editing; RS: critical inputs into the manuscript. HG will act as a study guarantor. All authors approved the final version of this manuscript.

Funding: None; Competing interests: None stated.

\section{References}

1. Chao DH, Zisman A, Pantuck AJ, Freedland SJ, Said JW, Belldegrun AS. Changing concepts in the management of renal oncocytoma. Urology. 2002;59:635-642.

2. Ahmad S, Manecksha R, Hayes BD, Grainger R. Case report of a symptomatic giant renal oncocytoma. International Journal of Surgery Case Reports. 2011;2(6):83-85.

3. Demos TC, Malone AJ Jr. Computed tomography of a giant renal oncocytoma. J Comp Assist Tomogr. 1988;12(5):899-900.

4. Banks KL, Cherullo EE, Novick AC. Giant renal oncocytoma. Urol. 2001;57(2):365-366.

5. Kiliç S, Altinok MT, Ipek D, Ergin H. Case report of a giant renal oncocytoma. Int Urol Nephrol. 2003;35(1):8384.

6. Young JR, Margolis D, Sauk S, Pantuck AJ, Sayre J, Raman SS. Clear cell renal cell carcinoma: discrimination from other renal cell carcinoma subtypes and oncocytoma at multiphasic multidetector CT. Radiology. 2013;267:444-453.

7. Campbell CS, Novick CA, Bukowski MR. Renal Tumours. In: Campbell's Urology. Vol. 2, 9th edition. Philadelphia, PA: WB Saunders; 2007: pp.1567-1637.

8. Dechet CB, Bostwick DG, Blute ML, Bryant SC, Zincke H. Renal oncocytoma: multifocality, bilateralism, metachronous tumor development, and coexistent renal cell carcinoma. J Urol. 1999;162(1):40-42. 